\title{
REPERCUSIONES LOCALES DE CAMBIOS GLOBALES: DINÁMICAS COMERCIALES EN LACIUDAD DE LEÓN
}

\author{
Alejandro LÓPEZ GONZÁLEZ \\ Departamento de Geografía y Geología-Universidad de León
}

Recibido: 21/08/2008

Aceptado: 26/06/2009

RESUMEN: El cambio de siglo ha significado transformaciones de cierta envergadura en las estructuras mercantiles presentes en la ciudad de León. Estas modificaciones tienen que ver con procesos novedosos, unos particulares a la construcción de la ciudad otros consecuencia del los nuevos escenarios socioeconómicos en los que se inscribe, que dejan huella de una manera u otra en la composición del comercio y en su localización.

En el presente artículo se pretende analizar los principales cambios registrados por el comercio local a fin de siglo y, en consecuencia, desentrañar el grado de ductilidad de las estructuras tradicionales y la presencia de nuevos agentes en el panorama mercantil. En definitiva, se estudia la relación, en buena medida de naturaleza dialéctica, entre el comercio tradicional y nuevos agentes comerciales al calor de los condicionantes introducidos por el crecimiento mismo de la ciudad y de la difusión de innovaciones tributarias de un nuevo contexto socioeconómico y cultural.

$P A L A B R A S C L A V E$ : globalización, comercio detallista, comerciantes, inmigración.

THE LOCAL REPERCUSSIONS OF GLOBAL CHANGE: COMMERCIAL DYNAMICS IN THE CITY OF LEÓN

ABSTRACT: The turn of the century has meant transformations of a certain size in commercial structures in the city of Leon. These changes relate to new processes, some particular to the construction of the city other consequence of the new socio-economic scenarios where falls, that make an impression one way or another in the composition of trade and its location.

The present article analyses the main changes made by the local trade to the end of the century, and thus unravel the extent of ductility of traditional structures and the presence of new players in the commercial landscape. Ultimately, studies the relationship, largely nature dialectic between traditional trade and new commercial agents in the heat of the constraints introduced by the same growth of the city and the diffusion of innovations tax for a new socio-economic and cultural context.

KEY WORDS: retail trade, retailers, inmigration.

\footnotetext{
${ }^{1}$ Este articulo recoge parcialmente los principales resultados del proyecto LE2006-2, "Lo local y lo global: cambios comerciales recientes en el área urbana de León", financiado íntegramente por la Universidad de León.
} 
RÉPERCUSSIONS LOCALES DES CHANGEMENTS GLOBAUX : DYNAMIQUES COMMERCIALES DE LA VILLE DE LEÓN

RÉSUMÉ: Le tournant du siècle a entraîné des transformations d'une certaine taille dans les structures commerciales dans la ville de León. Ces changements ont trait à de nouveaux procédés, certains particuliers à la construction de la ville, autre conséquence de la restructuration socio-économique des scénarios où les chutes, qui font l'impression, d'une manière ou d'une autre, dans la composition des échanges commerciaux et de son emplacement.

Le présent article analyse les principaux changements apportés par les commerce locaux à la fin du siècle, et donc de démêler la mesure de la ductilité des structures traditionnelles et de la présence de nouveaux acteurs dans le paysage commercial. En fin de compte, les études de la relation, en grande partie la nature dialectique entre le commerce traditionnel et les nouveaux agents commerciaux dans la chaleur des contraintes introduites par la même croissance de la ville et de la diffusion des innovations d'impôt pour un nouveau socio-économique et culturel.

MOTS-CLÉS: commerce détaillant, commerçants, inmigration.

\section{REPERCUSÕES LOCAIS DE ALTERAÇÕES GLOBAIS: DINÁMICAS COMERCIAIS NA CIDADE DE LEÓN}

RESUMO: A virada do século significou transformações de certo tamanhas nas estruturas comerciais na cidade de Leon. Estas alterações dizem respeito a novos processos, alguns particulares para a construção da cidade, outros consequência dos novos cenários sócio-económico nos que se insere que faça uma impressão, duma maneira ou de outra, na composição do comércio e da sua localização.

O presente artigo analisa as principais alterações introduzidas pelo comércio local até o final do século, e, portanto, desvendar o grau de ductilidade das estruturas tradicionais e a presença de novos jogadores na paisagem comercial. Em última análise, estudo a relação, em grande parte de natureza dialéctica, entre comércio tradicional e os novos agentes comerciais o calor das restrições introduzidas pelo mesmo crescimento da cidade e da difusão de inovações debidas a um novo contexto sócio-económico e cultural.

PALAVRAS CHAVE: comércio detalhado, comerciantes, imigração.

\section{REPERCUSIONES LOCALES DE TENDENCIAS GLOBALES}

El equipamiento comercial de una ciudad posee características internas propias y respuestas particulares a las influencias recibidas desde otros ámbitos de la actividad mercantil. Su tamaño y composición interna se ven condicionados por la dinámica de la demanda de bienes comerciales, por las innovaciones dentro de los canales comerciales en los que se integra o por su competitividad respecto a otros equipamientos comerciales de otras ciudades cercanas. En otras palabras, el comercio radicado en una ciudad vive en constante diálogo con condicionantes propios y ajenos que, en mayor o menor medida, permiten comprender su evolución más reciente.

En este contexto León posee un equipamiento comercial inmerso en un proceso evolutivo condicionado por la dialéctica entre sus particularidades y las tendencias hacia la homogenización impuestas por la actual globalización, fenómeno este último que también se extiende a la actividad comercial (BARATA, 
1999). Esta oposición parece parcialmente superada en las grandes ciudades, donde las nuevas formas comerciales alcanzan su máxima expresión y complejidad en las grandes ciudades (GARCÍA ESCALONA, 2000; CARRERAS, 2000); mientras que en ciudades medias como León, estas transformaciones no están aún lo suficientemente desarrolladas como para eclipsar el tejido mercantil tradicional.

De todos modos, y tras una década de bonanza económica, se consolida un mercado poliédrico. Atendiendo a la demanda, se caracteriza por un creciente poder adquisitivo y por unas pautas de consumo más complejas. Desde la perspectiva de la oferta se ha estructurado en dos segmentos claramente estructurados: el primero, innovador y dominado por la lógica del tamaño y la competitividad, es el campo de la gran distribución; el segundo, más débil y atomizado, lo constituye el pequeño comercio, emergiendo entre sus componentes más dinámicos, prácticas asociativas como vía de supervivencia.

Pero también se ha señalado que el equipamiento comercial leonés posee rasgos singulares que lo alejan de otros contextos comerciales, incluso cercanos geográficamente. En la raíz de la singularidad leonesa deviene una patente propensión al ahorro y la inversión en bienes raíces (la relación ente depósitos y créditos bancarios es claramente favorable a la primera, tal y como se desprende de la información publicada por el servicio de estadística del Banco de España), consecuente con una tasa de envejecimiento muy elevada tanto en la ciudad como en su área de mercado (LÓPEZ TRIGAL, CÓRTIZO y LÓPEZ GONZÁLEZ, 2007). La consecuencia directa del mayor ahorro está en tasas de consumo moderadas, que dan lugar a que el tejido comercial leonés, tanto cuantitativa como cualitativamente, está menos desarrollado en términos relativos, propiciando fugas de mercado hacia otras localidades (principalmente Asturias, donde una mayor propensión hacia al ahorro da lugar al desarrollo de un competitivo equipamiento comercial -BENITO DEL POZO y LÓPEZ GONZÁLEZ, 2004-). Otro rasgo singular deriva de la gran fuerza de la tradición: las plazas Mayor (el popularmente conocido como mercado de la verdura, los miércoles), Conde Luna (a diario), Colón (martes y viernes) y el dominical de Papalaguinda se convierten en frecuentados mercadillos al aire libre, permitiendo subsistir a un nutrido comercio ambulante.

La combinación de dinámicas globales y locales modela la evolución del espacio comercial en el interior de la ciudad que, a efectos de esta investigación, limito al territorio del municipio homónimo. De todos modos se parte de la base de que en este caso, más que otros si cabe, el escenario municipal es insuficiente. La urbe desborda claramente sus límites administrativos (LÓPEZ TRIGAL, 2002), surgiendo en los territorios limítrofes actividades comerciales que condicionan de manera directa la vida mercantil capitalina. 
El objetivo fundamental de este artículo estriba en identificar las transformaciones experimentadas por la actividad comercial leonesa entre 1995 y 2006. Supletoriamente se han definido otras metas que pretenden reflejar el impacto local de procesos territorialmente más amplios, como son la expansión de la gran distribución, la oposición entre la lógica del beneficio (empresa) frente a concepciones del negocio más próximas a la supervivencia (autónomo), y la aparición de los inmigrantes como nuevos actores en la oferta comercial.

Este trabajo se estructura en tres partes claramente diferenciadas y que tienen como objeto medir los cambios más relevantes experimentados por la oferta comercial leonesa: el primero se centra en aspectos funcionales, más concretamente en la correlación entre la venta de bienes de consumo frecuente y la de productos especializados; el segundo toma como referente la forma jurídica adoptada por los establecimientos, empleando como patrón de análisis la penetración en el tejido comercial de las sociedades mercantiles en un sector dominado tradicionalmente por los autónomos; finalmente, un apartado final se dedicará a un fenómeno incipiente pero en rápida expansión, como es la incorporación de los inmigrantes a la oferta comercial de la ciudad.

\section{Aspectos metodológicos}

Las fuentes primarias utilizadas fueron los padrones de contribuyentes de la Cámara de Comercio, y las secundarias la información ofrecida por anuarios (Indisa, en el campo de la distribución, y Fundación La Caixa, en lo que atañe a variables económicas genéricas). Los padrones de contribuyentes utilizan como base el Impuesto de Actividades Económicas, teniendo carácter universal pues toda actividad económica no agraria debe estar adscrita a la Cámara de Comercio con jurisdicción sobre el territorio donde tenga actividad. En consecuencia, es una fuente que, a pesar de sus insuficiencias metodológicas (clasificación de actividades menos operativa que la CNAE), ofrece una información más completa que la aportada por los registros mercantiles (fuente que sólo incluye sociedades, siempre que tengan la sede social en su ámbito territorial, lo que excluye a muchas actividades económicas).

Las magnitudes empleadas se remiten a dos marcos espaciales de referencia: el conjunto del municipio de León y los distritos censales en los que se divide. El escenario fundamental empleado en este análisis es el distrito, su elección se explica por tres razones fundamentales: se reduce al mínimo los problemas en la delimitación de áreas homogéneas dentro de la ciudad, se emplean unidades de análisis de dimensiones demográficas similares (el tamaño del distrito en León varía entre 10.000 y 20.000 habitantes, parámetros de los que escapan únicamente tres distritos, mucho menos poblados-concretamente el 1, 8 y 9-), y se 
cuenta con la posibilidad de establecer comparaciones con otras fuentes como el Padrón Municipal de Habitantes.

El inconveniente que poseen los distritos censales deriva de su misma delimitación, ya que abarcan extensas superficies que pueden incluir en su interior sectores urbanos de características muy dispares. Esta eventualidad, constatada en el caso de León, desemboca en afirmaciones que, en ocasiones, pueden no ser una imagen fiel de la realidad urbana leonesa (distorsión que se intenta paliar a partir de cartografía que emplea como base las secciones censales, aunque empleando información menos fiable al basarse en información de más difícil manejo).

De todos modos, se debe señalar que el distrito censal como marco de análisis ya ha sido aplicado por el autor en otras ciudades y en la misma línea temática (LÓPEZ GONZÁLEZ, 2001a, 2001b y 2003), y por otros autores en la ciudad de León (GONZÁLEZ GONZÁLEZ, 1987 y 1999; GONZÁLEZ GONZÁLEZ y PÉREZ LLAMAZARES, 2000) con resultados en ambos casos satisfactorios.

Los distritos censales (MAPA 1) han sido estructurados en tres categorías en virtud de su situación dentro del conjunto urbano y sus características internas (funcionalidad y morfología). Una primera se ha denominado "centro", se extiende por los distritos 1 y 2 englobando el ensanche y una pequeña porción del casco histórico; una segunda la he etiquetado como "barrios" y abarca la mayor parte del municipio (distritos 3, 4, 5, 6, 7 y 10), incluyendo un ámbito muy heterogéneo como es la mayor parte del casco antiguo, los sectores que expanden hacia norte y sur desde el ensanche, los barrios que crecieron espontáneamente al calor de polos tradicionales de actividad (El Crucero, San Mamés o El Ejido), o los polígonos residenciales que ensancharon el tejido urbano en las últimas décadas; por último, el escaso marco periurbano dentro del municipio capitalino (distritos 8 y 9), con áreas urbanas no consolidadas hacia el sur de la ciudad (Puente Castro y Armunia).

Sobre esta estructura de fuentes y esta demarcación geográfica se pretende ofrecer una visión, lo más sintética posible, de los cambios estructurales sufridos por el comercio leonés entre 1995 y 2006. Se han primado aquellos aspectos concretos juzgados como reveladores de los procesos de cambio: evolución de las actividades detallistas según grandes grupos (comercio al detalle de consumo frecuente -venta de productos de alimentación y comercio mixto- $y$ especializado - establecimientos centrados en la venta de familias concretas de productos no alimentarios-), expansión de las actividades en manos del comercio con cierto grado de modernización (formas societarias -sociedades colectivas, anónimas y limitadas-, frente al tradicionalismo predominante entre los comer- 
ciantes autónomos - establecimientos regentados por personas físicas-), y presencia del comercio en manos de comunidades inmigrantes.

\section{VARIACIONES EN LA OFERTA DETALLISTA}

El período analizado se caracteriza por una progresión del equipamiento detallista considerado en su conjunto (en 1995 el comercio minorista sumaba 3.255 actividades en el padrón de la Cámara de Comercio, en 2006 alcanzaba 3.440 actividades, un 5,68 \% más). Pero el crecimiento del comercio contemplado como un todo encubre fuertes contrastes entre el detallismo de consumo frecuente y el especializado, disparidades que conllevan la recomposición de ambos grupos en términos relativos y espaciales.

\section{La crisis de comercio de bienes de consumo frecuente}

La venta final de bienes de consumo frecuente está viviendo desde hace décadas una transformación profunda, que tiende hacia la concentración de este tramo de la distribución en un elenco cada vez más reducido de grandes compañías; en el origen de esta crisis se encuentra, por una parte, la mutación en las preferencias y estructura de gasto de los consumidores (según el INE entre 1998 y 2005 el gasto en alimentación en ciudades de más de 100.000 habitantes ha retrocedido desde el 18,12\% hasta el 16,06\% de los presupuestos familiares), $\mathrm{y}$, por otra, el creciente poder de mercado de las grandes empresas de distribución. Este contexto, adverso a los formatos tradicionales (ultramarinos, pequeñas tiendas de alimentación en fresco), ha conllevado su progresiva sustitución por establecimientos en régimen de autoservicio. Únicamente factores extraeconómicos (el pequeño comercio como medio de subsistencia, una legislación que ha pretendido limitar desde 1996 la expansión de las grandes superficies, el papel de los ya agónicos mercados de abastos, el impacto de la inmigración) han contribuido a que sobrevivan aún bastantes pequeños establecimientos. Particularmente, en las medias y pequeñas ciudades, la resistencia del pequeño comercio tradicional es superior gracias al poder de presión de los pequeños comerciantes y al menor atractivo que ofrecen para la gran distribución, atenuando y postergando la decadencia de este segmento concreto de la distribución final.

De todos modos, los cambios en oferta y demanda implican la reducción del número de establecimientos debido a la concentración del mercado de estos productos en un número decreciente de empresas, aquéllas que cuentan con la suficiente capitalización para acometer las inversiones necesarias para una mejor satisfacción de la demanda. En definitiva, la tendencia apunta a que la cuota del comercio de consumo frecuente sobre el equipamiento detallista sea cada vez menor. 
Lo comentado en el párrafo anterior responde a una visión estructural, necesariamente abstracta y limitada a magnitudes numéricas. Una perspectiva diferente viene de la mano de la introducción de la variable espacio, pues no será idéntica la merma del peso de los puntos de venta de bienes de consumo frecuente en las áreas centrales que en las áreas periféricas; ni tampoco será homogénea la penetración de la distribución en régimen de autoservicio en los distintos barrios y sectores.

En términos cuantitativos el retroceso de la oferta de bienes de consumo frecuente es patente. Tanto en términos absolutos como relativos este tipo de detallismo no deja de perder presencia, constatándose este hecho en el conjunto de la ciudad y en sus distritos (CUADRO 1): globalmente pierde 179 actividades (un $-11,51 \%$ menos), lo que lleva a que retroceda desde un tercio de las actividades detallistas hasta el presente $28,37 \%$.

Cuadro 1. Comercio detallista de consumo frecuente por distritos

\begin{tabular}{lrrrrr}
\hline & \multicolumn{2}{c}{ } & \multicolumn{2}{c}{2006} & \multirow{2}{*}{ Variación } \\
\cline { 2 - 5 } & Activ. & $\%$ & Activ. & $\%$ & \\
\hline Distrito 1 & 145 & 13,15 & 116 & 11,89 & $-20,00$ \\
Distrito 2 & 111 & 10,06 & 95 & 9,73 & $-14,41$ \\
\hline CENTRO & 256 & 23,21 & 211 & 21,61 & $-17,58$ \\
\hline Distrito 3 & 131 & 11,88 & 139 & 14,24 & 6,11 \\
Distrito 4 & 138 & 12,51 & 139 & 14,24 & 0,72 \\
Distrito 5 & 132 & 11,97 & 102 & 10,45 & $-22,73$ \\
Distrito 6 & 134 & 12,15 & 124 & 12,70 & $-7,46$ \\
Distrito 7 & 167 & 15,14 & 148 & 15,16 & $-11,38$ \\
Distrito 10 & 79 & 7,16 & 66 & 6,76 & $-16,46$ \\
\hline BARRIOS & 781 & 70,81 & 718 & 73,57 & $-8,07$ \\
\hline Distrito 8 & 14 & 1,27 & 12 & 1,23 & $-14,29$ \\
Distrito 9 & 27 & 2,45 & 29 & 2,97 & 7,41 \\
\hline PERIURBANO & 41 & 3,72 & 41 & 4,20 & 0,00 \\
\hline LEÓN & 1.103 & 100,00 & 976 & 100,00 & $-11,51$ \\
\hline
\end{tabular}

FUENTE: Elaboración propia a partir del censo de electores de la Cámara de Comercio de León.

Nota: En este cuadro, así como en los sucesivos, los valores atribuidos a León y al agregado de distritos censales no coinciden debido a la existencia de un reducido contingente de actividades imposible de atribuir a un distrito en concreto.

Por distritos el retroceso es, como es lógico, la pauta dominante. Únicamente los distritos 3, 4 y 9 se presentan como notas discordantes, pues en términos absolutos o permanecen inalterables (el distrito 4) o han registrado leves incrementos, motivados bien por equipamientos inadecuados para un fuerte crecimiento demográfico (distrito 3) bien por unos niveles de partida ciertamente es- 
cuálidos (distrito 9). En lo que a las reducciones se refiere, son máximas en los distritos $1(-20,00 \%)$ y $5(-22,73 \%)$ : en el primer caso influye de forma manifiesta la crisis sostenida del mercado de abastos, la plaza Conde Luna (más de la mitad del decrecimiento de este distrito se explica a partir de cierres en establecimientos de alimentación en fresco); en el segundo la decadencia comercial de un espacio que incluye sectores degradados (barrio de San Martín en el casco histórico), mal comunicados con el centro urbano y/o castigados por la competencial del principal hipermercado del área urbana de León (Santa Ana, Polígono X).

De todos modos, si nos remitimos al peso relativo de cada distrito, se ha asistido a algunas transformaciones que visualizan una relativa decadencia del centro de la ciudad a favor de los barrios:

Los distritos que ocupan el centro de la ciudad han mermado su presencia en el reparto del detallismo de consumo frecuente. En la década incluida dentro de este trabajo ha pasado de un $23,21 \%$ a un $21,61 \%$, cifras aún altas gracias a la localización en el distrito 1 del único mercado de abastos de la ciudad y que inciden en que su peso aún permanezca claramente por encima de su entidad demográfica (en 2006 alcanzaban el 13,20\% de la población leonesa).

Los que califico como barrios han incrementado visiblemente su contribución sobre el conjunto de la ciudad. En 1995 suponían el 70,81 \%, mientras en 2006 ya representaban el 73,57\% del detallismo de consumo frecuente, incremento al que contribuyen significativamente los distritos 3 y 4 . Estas cifras reafirman el carácter de comercio de proximidad de este ramo, quedando cada vez más anclado a los usos residenciales (en 2006 la población de estos distritos representaba el 81,81\% del total municipal).

Finalmente los dos distritos periurbanos poseen un equipamiento muy poco desarrollado. Las variaciones se pueden calificar casi como aleatorias y de difícil interpretación: ya se ha referido la expansión de este tipo de comercio en el distrito 9 (que se nos antoja lógica); en contraste el distrito 8 retrocede por encima del promedio urbano, aunque siempre en cifras absolutas ciertamente exiguas. El resultado final es que el espacio periurbano situado dentro de los límites municipales leoneses ha progresado desde el 3,72 \% de 1995 al 4,20 \% de 2006.

Abandonando la visión ofrecida por los distritos y tomando el nivel máximo de desagregación, las secciones censales, se obtiene una visión bastante reveladora sobre la suerte del comercio al por menor de consumo frecuente (MAPA 2). Se observa una tendencia divergente entre los distritos centrales y los barrios, mientras en los primeros predominan los retrocesos en la actividad comercial, 
en los segundos se aprecia lo contrario. Como elemento más significativo es la disposición espacial de los retrocesos e incrementos en las secciones situadas en los distritos barriales: se resuelve como una yuxtaposición de sectores en franca decadencia (El Crucero, gran parte de Mariano Andrés y del sector antiguo de los ejes San Mamés-Nocedo, El Ejido), con otros en expansión (Soto del Bernesga, Eras de Renueva, polígono residencial de San Mamés, La Palomera-La Torre, La Chantría y sectores adyacentes). Esta alternancia entre sectores decadentes y expansivos ilustra la íntima relación entre población y comercio de consumo frecuente, pues los primeros se caracterizan por la pérdida de efectivos demográficos y el envejecimiento de los mismos, frente a la progresión y rejuvenecimiento de los segundos.

\section{La expansión del comercio especializado}

En la década que abarca este estudio el comercio especializado ha seguido un camino abiertamente divergente en comparación con el dedicado a la venta de bienes de consumo frecuente (CUADRO 2). El creciente peso de los bienes no alimentarios en la composición del gasto de las familias, la gran heterogeneidad de la oferta de bienes de consumo esporádico y la menor agresividad de los formatos empleados habitualmente por la gran distribución en este ramo contribuyen a que, cuantitativamente, las actividades comerciales encuadradas en este sector hayan crecido entre 1995 y 2006 (en el municipio de León han pasado de 2.150 actividades a 2.464 , lo que supone un crecimiento del $14,50 \%$ ).

Cuadro 2. Evolución del detallismo de consumo esporádico

\begin{tabular}{lrrrrr}
\hline & \multicolumn{2}{c}{1995} & \multicolumn{2}{c}{2006} & \multirow{2}{*}{ Variación } \\
\cline { 2 - 5 } & Activ. & $\%$ & Activ. & $\%$ & \\
\hline Distrito 1 & 466 & 21,65 & 454 & 18,43 & $-2,58$ \\
Distrito 2 & 491 & 22,82 & 510 & 20,70 & 3,87 \\
\hline CENTRO & 957 & 44,47 & 964 & 39,12 & 0,73 \\
\hline Distrito 3 & 143 & 6,64 & 201 & 8,16 & 40,56 \\
Distrito 4 & 229 & 10,64 & 286 & 11,61 & 19,93 \\
Distrito 5 & 227 & 10,55 & 215 & 8,73 & $-5,29$ \\
Distrito 6 & 229 & 10,64 & 293 & 11,89 & 27,95 \\
Distrito 7 & 178 & 8,27 & 313 & 12,70 & 75,84 \\
Distrito 10 & 104 & 4,83 & 94 & 3,81 & $-9,62$ \\
\hline BARRIOS & 1.110 & 51,58 & 1.402 & 56,90 & 26,31 \\
\hline Distrito 8 & 28 & 1,30 & 31 & 1,26 & 10,71 \\
Distrito 9 & 23 & 1,07 & 50 & 2,03 & 117,39 \\
\hline PERIURBANO & 51 & 2,37 & 81 & 3,29 & 58,82 \\
LEÓN & 2.152 & 100,00 & 2.464 & 100,00 & 14,50 \\
\hline
\end{tabular}

FUENTE: Elaboración propia a partir del censo de electores de la Cámara de Comercio de León. 
A nivel distrito se puede hablar, en general, de un comportamiento positivo del comercio especializado. De todos modos no se aprecia una uniformidad total y absoluta, pues mientras la mayoría han visto crecer el número de actividades comerciales especializadas (destacan los distritos 7 y 9), en tres se han apreciado retrocesos (concretamente los distritos 1,5 y 10 ).

En los distritos centrales este segmento parece haber entrado en un período de madurez, pues las variaciones registradas son muy pequeñas (en el distrito 1 ha retrocedido en un $-2,58 \%$, en el 2 ha crecido tan sólo un 3,87 \%). Esta circunstancia se antoja lógica, pues ha concentrado históricamente el grueso de la oferta mercantil de mayor rango (CORTIZO, 1999, p. 111), registrando a lo largo del periodo estudiado una marcada tendencia regresiva (en 1995 representaban el $44,47 \%$ y en 2006 el 39,12\%) perdiendo atractivo para muchos negocios frente a otras localizaciones periféricas.

En los barrios el dinamismo es la nota dominante, crecimiento ayudado por la aparición de nuevas centralidades alternativas al centro tradicional de la ciudad; como consecuencia el porcentaje de actividades comerciales especializadas situadas en estos distritos crece desde el 51,57\% hasta el 57,00\%. Los distritos donde la progresión de este segmento es más visible son el 3 (40,56 \%), 4 $(27,95 \%)$ y $7(75,84 \%)$, y en todos ellos interviene algún factor de arrastre que posibilita la consolidación de focos de actividad comercial especializada: en el 3 la consolidación del nuevo polígono de Eras de Renueva y la acumulación de equipamientos en el mismo (efecto que se puede prorrogar y amplificar en el futuro inmediato ya que se está construyendo en Eras de Renueva el que será segundo centro comercial de la ciudad), en el 6 la repercusión de El Corte Inglés en las calles adyacentes y en el 7 el influjo de la apertura del centro comercial Espacio León, que por si sólo acoge a más de una centena de establecimientos. En un nivel intermedio se sitúa el distrito 4, que acusa cierto estancamiento en su eje comercial tradicional (la calle San Mamés), sin consolidar nuevas centralidades en los nuevos polígonos residenciales allí situados. Finalmente los distritos 5 y 10 sufren una evidente decadencia (retrocesos del -5,29\% y -9,62\%), lo que pone de manifiesto aún más si cabe su débil vitalidad mercantil y escaso atractivo motivado por cierto nivel de degradación y por su mala conectividad con el resto del tejido urbano.

Los distritos periurbanos poseen comportamientos diferenciados, tibio en el caso del distrito 8 (crece un 10,71\%), extraordinariamente vivaz en el 9 $(117,39 \%)$, lo que les lleva a pasar de un pobre $2,37 \%$ del detallismo especializado leonés a un 3,29\%. Se trata de espacios donde el comercio especializado responde a características muy particulares, pues se encuentra dominado por segmentos de la distribución final necesitados de suelo (exposición de bienes de tamaño voluminoso), con stocks sometidos a rotaciones extraordinariamente 
lentas (venden productos cuyo uso se prolonga durante años) y precisan localizaciones accesibles para el conjunto del área urbana (por tanto, tienden a buscar las principales vías de acceso). En el caso del distrito 8 su dinamismo se vincula a los espacios lineales a lo largo del acceso desde Valladolid, que adquieren su verdadera proyección más allá de los límites municipales capitalinos (Alto del Portillo, Arcahueja y Valdelafuente), lo que juega en contra de este distrito. Situación bien distinta es la que se da en el distrito 9, que abarca extensos desarrollos lineales a lo largo de las carreteras de Astorga y Zamora, a los que se une la parte del polígono industrial de León incluida dentro del municipio leonés, donde existen bastantes establecimientos comerciales.

En definitiva, desde una perspectiva general se puede hablar con toda propiedad de claro esquema centro-periferia, donde el sector central se estanca o pierde peso frente a los sectores pericentrales y periurbanos, repitiendo esquemas ya descritos por R. P. DESSE (2001) para algunas ciudades medias del oeste de Francia. Como caso particular, únicamente entrevisto a partir del análisis de las cifras correspondientes a los distritos 1, 4 y 5 (parcialmente se extienden por la parte antigua de la ciudad), destacar la paradigmática desertificación comercial del casco histórico, lejos de su antaño dinamismo de décadas pasadas (TOMÉ, 1979). Salvo los entornos de las calle Ancha, Rúa y Conde Luna, el grueso del casco histórico queda sumido en el práctico abandono (barrio de Santa Marina) o sustituido por usos orientados al ocio nocturno y vespertino (barrio de San Martín, el popularmente denominado barrio Húmedo); compartiendo muchos de los problemas presentados por otras ciudades con recintos históricos de características semejantes (CAMPESINO, 1999; MOLINA, 2002).

Una imagen complementaria a la vista más arriba nos la ofrece la cartografía basada en secciones censales (MAPA 3). La tendencia expansiva general se traduce, lógicamente, en el hecho de que el número de secciones donde ha crecido el número de actividades de este tipo es superior a las que las han visto descender, destacando tres puntos concretos (la sección donde se ubica el Centro Comercial Espacio León -al noroeste del casco urbano-, donde se sitúa El Corte Inglés -al sur- y el campus universitario -al noroeste, aunque esta última con un papel netamente anecdótico-). Las secciones censales que registran retrocesos se extienden por buena parte de los distritos centrales (Ensanche) y en barrios pericentrales (casco antiguo, El Ejido, las inmediaciones de la Avenida de Asturias y Álvaro López Núñez y El Crucero), todas ellas coincidentes con sectores urbanos consolidados y, en ocasiones, con síntomas de obsolescencia. En resumen, la dinámica del comercio detallista especializado muestra en León un comportamiento que se ajusta bastante al modelo centro-periferia. 


\section{LÓGICAS CAPITALISTAS Y LÓGICAS DE SUBSISTENCIA}

Hasta el momento se ha analizado el sector comercio desde la perspectiva de la estructura de la oferta, construida a partir de la interpretación del padrón de electores de la Cámara de Comercio. En este epígrafe se pretende poner de manifiesto los cambios más significativos que han sufrido los agentes comerciales, que a mi entender son la progresión de las formas societarias en el detallismo leonés (que en sentido inverso se puede interpretar como la crisis del comercio tradicional), y la aún incipiente aparición de la inmigración entre los comerciantes locales (que, en algunos tramos concretos de la oferta al detalle, sustituyen parcialmente al pequeño vendedor autóctono).

\section{La expansión de las formas jurídicas societarias en el detallismo leo- nés}

En el plano empresarial el comercio se ha caracterizado por un elevado minifundismo, propio de un sector tradicionalmente poco competitivo y volcado a satisfacer la demanda de mercados locales. En este contexto la casi totalidad de los establecimientos eran negocios de carácter familiar, económicamente precarios y que respondían a lógicas de subsistencia más que a un espíritu empresarial; desde el punto de vista jurídico operaban como empresarios individuales bajo el régimen de autónomos. Con los cambios sufridos por la actividad comercial en las últimas décadas se ha ido consolidando un nuevo modelo de comerciante, más competitivo y dominado por lógicas de mercado, lo que implica el predominio de la idea del beneficio en la actividad mercantil; en otras palabras, el establecimiento-empresa se impone sobre el de carácter familiar, y, desde una perspectiva jurídica, serán las sociedades colectivas y las mercantiles reflejos de una nueva actitud mercantil más adecuada a la nueva realidad del comercio.

Desde la perspectiva enunciada en el párrafo precedente se puede, pues, utilizar la proporción de establecimientos propiedad de sociedades como indicador de dos fenómenos correlacionados: el grado de modernización del tejido mercantil leonés y la crisis del comercio tradicional. Este último aspecto resulta especialmente relevante, en especial si se considera que abre un hueco susceptible de cubrirse por otros agentes (los inmigrantes).

El comercio tradicional, identificado en buena medida por la figura del autónomo, se ve castigado por innovaciones económicas que desde hace pocas décadas domina el sector comercial y, más recientemente aún, el mercado leonés. El comercio como actividad dirigida a la obtención de un beneficio, visión impuesta desde una óptica liberal de la actividad mercantil, mina la viabili- 
dad del pequeño comercio más tradicional, donde proliferan comportamientos más cercanos a la subsistencia que a la maximización del beneficio.

Los factores que castigan al pequeño comercio se asocian a intensos cambios en la demanda (nuevas tendencias en el consumo, incremento de la movilidad del consumidor y cambio en las costumbres de compra), en la oferta (nuevos formatos y técnicas de venta, con requerimientos financieros y formativos que elevan los costes para el comerciante) y en las expectativas del mercado de trabajo (mayor atractivo de otras profesiones frente al ejercicio de la actividad comercial). Todos estos factores implican que el comerciante tradicional se encuentre en una situación de desventaja frente a las grandes empresas de distribución, desapareciendo muchos puntos de venta bien por ser escasamente competitivos bien por la falta de continuidad de muchos negocios familiares tras la jubilación del titular.

El CUADRO 3 analiza los cambios en el comercio leonés utilizando como indicador el grado de penetración de las formas societarias en el tejido comercial leonés, información complementada por el CUADRO 4 que pretende medir la resistencia del comercio tradicional a partir de la variación del número de punto de venta propiedad de autónomos.

Cuadro 3. Grado de penetración de formas societarias

\begin{tabular}{lrrrrr}
\hline & \multicolumn{2}{c}{1995} & \multicolumn{2}{c}{2006} & Diferencia \\
\cline { 2 - 5 } & $E$ & $\%$ & $E$ & $\%$ & \\
\hline Distrito 1 & 188 & 32,87 & 306 & 55,23 & 62,77 \\
Distrito 2 & 249 & 38,66 & 355 & 54,95 & 42,57 \\
\hline CENTRO & 437 & 37,77 & 661 & 55,08 & 51,26 \\
\hline Distrito 3 & 74 & 24,58 & 170 & 43,70 & 129,73 \\
Distrito 4 & 78 & 20,21 & 174 & 40,85 & 123,08 \\
Distrito 5 & 91 & 22,98 & 145 & 42,40 & 59,34 \\
Distrito 6 & 115 & 29,26 & 216 & 48,32 & 87,83 \\
Distrito 7 & 117 & 30,87 & 250 & 52,97 & 113,68 \\
Distrito 10 & 56 & 28.00 & 65 & 49,75 & 16,07 \\
\hline BARRIOS & 531 & 25,84 & 1.020 & 45,45 & 92,09 \\
\hline Distrito 8 & 16 & 32,00 & 27 & 52,94 & 68,75 \\
Distrito 9 & 47 & 49,47 & 87 & 69,60 & 85,10 \\
\hline PERIURBANO & 63 & 43,45 & 114 & 64,77 & 0,95 \\
LEÓN & 1.062 & 30,80 & 1.816 & 49,75 & 70,99 \\
\hline
\end{tabular}

FUENTE: Elaboración propia a partir del censo de electores de la Cámara de Comercio de León.

A nivel general se observa una notable progresión de las sociedades en el conjunto del comercio leonés. En tan sólo una década han crecido prácticamente un 
$71,00 \%$, lo que permite pasar del millar escaso de establecimientos de 1995 a los 1.816 actuales. En términos relativos el avance de las formas societarias ha sido notable, pasa de una situación abiertamente minoritaria $(30,80 \%)$ a otra en la que alcanza prácticamente la paridad con los negocios en manos de autónomos $(49,75 \%)$. La lectura de estos datos apunta a un fuerte impulso de la profesionalización en la gestión comercial y a un retroceso de la visión familiar y tradicional de esta actividad económica. Por tanto, parece evidente la crisis y decadencia del pequeño comercio tradicional, imagen que se refuerza si se comprueba la evolución del número de establecimientos en manos de autónomos: en términos absolutos retrocede desde los 2.386 puntos de venta de 1995 hasta los 1.834 de 2006, o, lo que es lo mismo, en diez años han desaparecido (o reconvertido en sociedades) 552 establecimientos regentados por autónomos (un $23,13 \%$ menos).

Cuadro 4. Evolución de los establecimientos regentados por autónomos

\begin{tabular}{lrrr}
\hline & 1995 & 2006 & Diferencia \\
\hline Distrito 1 & 384 & 248 & $-35,42$ \\
Distrito 2 & 336 & 291 & $-13,39$ \\
\hline CENTRO & 720 & 539 & $-25,14$ \\
\hline Distrito 3 & 227 & 219 & $-3,52$ \\
Distrito 4 & 308 & 252 & $-18,18$ \\
Distrito 5 & 305 & 197 & $-35,41$ \\
Distrito 6 & 278 & 231 & $-16,91$ \\
Distrito 7 & 262 & 222 & $-15,27$ \\
Distrito 10 & 144 & 103 & $-28,47$ \\
\hline BARRIOS & 1.524 & 1.224 & $-19,68$ \\
\hline Distrito 8 & 34 & 24 & $-29,41$ \\
Distrito 9 & 48 & 38 & $-20,83$ \\
\hline PERIURBANO & 82 & 62 & $-24,39$ \\
\hline LEÓN & 2.386 & 1.834 & $-23,13$ \\
\hline
\end{tabular}

FUENTE: Elaboración propia a partir del censo de electores de la Cámara de Comercio de León.

En los distritos centrales, tradicional ubicación de los comercios con mayor cifra de negocio, la tasa de crecimiento de las sociedades es menor $(62,77 \%$ en el distrito 1 y $42,57 \%$ en el 2), si bien parten de unos niveles de partida superiores a otros barrios de la ciudad $(32,87 \%$ para el distrito 1 y $38,66 \%$ para el 2 ), a lo que se añade un grado de organización notable del pequeño comercio (Centro Comercial Abierto León Gótico). De todos modos, pese a los avances organizativos alcanzados del pequeño comercio, en la década analizada se ha asistido a una destrucción de establecimientos propiedad de autónomos en términos netos: 136 en el distrito 1 (un $-35,43 \%$ menos, cifra elevada e impul- 
sada por la prolongada crisis del núcleo comercial en torno al mercado de Conde Luna) y tan sólo 45 en el distrito 2 (retroceso cifrado en un -13,39 \%, uno de los bajos de la ciudad).

En los barrios los incrementos del número de establecimientos en manos de sociedades alcanzan los valores máximos, pues, con la excepción de los distritos 5 y 10, se supera claramente tanto el promedio de la ciudad como las tasas ofrecidas por los distritos centrales. Los que más crecen son los distritos 3,4 y 7, áreas donde se duplica el número de puntos de venta en estas condiciones; más modesto fue el crecimiento registrado por estos establecimientos en el distrito 6 , aunque no por ello despreciable al cifrarse su tasa de variación en un $87,83 \%$. El abierta oposición, los distritos 5 y 10 permanecieron al margen de la dinámica general, en especial el segundo (tan sólo sumó un 16,07 \% más), mientras que el primero alcanzó una cifra equiparable a la registrada por los distritos centrales (un 59,34\%) aunque por razones que se antojan diferentes. La tasa de penetración de las sociedades ha variado sustancialmente, pues en 1995 se situaban en torno a los 20-30 puntos (el mínimo correspondía al 20,21\% del distrito 6, el máximo al 30,87 \% del distrito 7), y diez años más tarde crecen hasta un rango de valores situado en la banda del 40-50 \% (mínimo para el distrito 10 , con un 38,69 \%; máximo para el 7 con un 52,97\%). Si se da la vuelta al discurso mantenido hasta el momento y se pasa a considerar la evolución del pequeño comercio más tradicional, se encuentra la misma tónica de destrucción de establecimientos en términos netos, aunque se detectan ciertas variaciones que introducen matizaciones ciertamente interesantes: en primer lugar, únicamente la desaparición de este tipo de establecimientos alcanza tintes preocupantes en aquellos distritos en clara decadencia desde una perspectiva general (el 5 , donde retroceden un $-35,41 \%$, y el 10, con un $-28,47 \%$ ); en el resto el cierre de este tipo de establecimientos no es tan alarmante (van desde un -3,52 en el distrito 3 hasta el $-18,18 \%$ del 4 ), lo que remite a la mayor resistencia del pequeño comercio tradicional en aquellos barrios donde se abren más oportunidades de negocio e incluso donde aparecen incipientes iniciativas asociativas (en torno a la calle San Mamés, en el distrito 4).

Un caso aparte lo constituyen los distritos periurbanos, pues parten de tasas de penetración de las formas societarias sensiblemente altas $(32,00 \%$ de los establecimientos en el distrito $8,49,47 \%$ en el 9) y, a pesar de ello, siguen creciendo a buen ritmo (en el primero a niveles levemente inferiores al promedio capitalino, con un $67,75 \%$; más acelerado en el segundo, un $85,10 \%$; lo que desemboca en que, en la actualidad, la presencia de las sociedades alcance niveles muy elevados $(52,94 \%$ en el 8 y $69,60 \%$ en el 9$)$. Estos datos son indicativos de la naturaleza de la actividad comercial aquí radicada; como se ha señalado más atrás, acogen a un gran número de negocios que requieren unas infraes- 
tructuras de tamaño considerable y, por tanto, precisan de elevadas inversiones lo que aconseja marcos jurídicos más complejos que los requeridos por el pequeño comercio más tradicional. En ambos sectores, con un mercado irrelevante en términos numéricos y con localizaciones poco atractivas fuera del comercio antes mencionado, el pequeño comercio fue siempre residual y caracterizado por una supervivencia siempre precaria (en el período considerado los establecimientos propiedad de autónomos han caído un $-29,41 \%$ en el distrito 8 y un $20,83 \%$ en el 9$)$.

La rápida implantación del empresariado comercial se confirma a nivel de sección censal (mapa 4). Los incrementos son generalizados (destacan las secciones donde se ubican el centro comercial Espacio León y El Corte Inglés), convirtiéndose en anecdóticas las secciones donde se registran retrocesos, no sólo por su número (diez) sino por su distribución espacial (aleatoria, sin constituir núcleos compactos) y por su situación en el contexto urbano (sin entidad alguna y de carácter marginal).

a. Manifestaciones espaciales de la pugna entre el pequeño comercio tradicional y la gran distribución

Hasta el momento se ha repasado el grado de penetración de las formas jurídicas societarias en el tejido comercial leonés, entendido como indicio del proceso de modernización estructural del sector y de la irrupción de formas de entender la actividad mercantil diferentes de las concepciones tradicionales. También se ofreció una visión cuantitativa sobre el comerciante autónomo, interpretado a su vez como indicador de la resistencia de las modalidades tradicionales del comercio. Este procedimiento, simplificación de una realidad más compleja, debe ser acompañado de un análisis de las modalidades espaciales más llamativas de la irrupción de la gran distribución -libre servicio y centros comerciales$\mathrm{y}$ de las estrategias diseñadas por ciertas asociaciones de pequeños comerciantes -plasmadas en los denominados centros comerciales abiertos-.

En lo que atañe al libre servicio se han utilizado datos de los anuarios de distribución publicados por Indisa para 1996 y 2006-2007. De la comparación entre ambos años se desprende una rápida progresión de las superficies ocupadas por hipermercados y supermercados (en el municipio de León pasan de 34.421 $\mathrm{m}^{2}$ de sala de venta en 1995 a $60.232 \mathrm{~m}^{2}$ en 2006, un 74,99\% más), crecimiento que se repite de manera más o menos acusada en todos los distritos a excepción del 9 y el 10 (los máximos incrementos se corresponden a los distritos 3, con un $167,06 \%$ más, y 4, con el 240,79\%; como contrapunto el distrito 10 ha perdido un $-67,60 \%$ ). A lo largo de este período la cuota de los cuatro grupos de distribución más potentes en cada año crece levemente (en 1995 Continente, Grupo Unigro, Cenco y Grupo León aglutinan el 78,94 \% de la superficie de venta; en 
2006 Carrefour, El Árbol, Alimerka y Mercadona el 79,96 \%), mientras el número de empresas que operaba en este tramo de la distribución retrocedía sensiblemente (de 14 pasa a nueve), lo que supone que a lo largo del período considerado el libre servicio en la ciudad ha progresado en términos de concentración empresarial y restricción del grado de competitividad. Un último indicador de este proceso de incremento del poder de las grandes empresas de distribución, es el tamaño promedio de los puntos de venta incluidos en esta categoría. A lo largo de estos diez años ha crecido visiblemente $\left(717 \mathrm{~m}^{2}\right.$ en 1995 , promedio que cae a 553,38 si se excluye el hipermercado radicado en la ciudad; $885,76 \mathrm{~m}^{2}$ en $2006,752,57 \mathrm{~m}^{2}$ si se consideran únicamente los supermercados).

En definitiva, el sector del libre servicio es un ejemplo manifiesto de la sustitución del pequeño comercio por la gran distribución en el comercio de consumo frecuente. También, si nos fijamos de nuevo en la evolución de los promedios de superficie por establecimiento, es un reflejo de un proceso de reacomodo de la gran distribución. En la década de 1980 se centró en el segmento del hipermercado, pero a partir de mediados de los años 1990, coincidiendo con las medidas restrictivas frente a las grandes superficies consecuencia de la ley de comercio interior de 1996, deciden diversificar su actividad creciendo mediante formatos más pequeños, tal como se ha demostrado en el caso de Valladolid (CALDERÓN Y GARCÍA CUESTA, 2006), apoyándose en su poder negociador dentro del canal de distribución para desplazar a empresas menos competitivas (CRUZ, 1999).

En lo relacionado con los centros comerciales tenemos que dirigir una mirada a la única iniciativa de este tipo existente en la ciudad (el centro comercial Espacio León), aunque en un futuro próximo se verá acompañado por un segundo centro comercial de características semejantes. En León los centros comerciales no han estado presentes hasta fechas muy recientes, pues el hipermercado Carrefour no puede ser considerado como tal sino más bien como el núcleo de un parque comercial (un hiper con una pequeña galería comercial adosada, una superficie especializada en juguetes - toys'ur's-, un supermercado Dia, un taller de mecánica rápida Feu Vert y un McDonalds). En octubre de 2004 se inaugura el centro comercial Espacio León, y la misma fecha de apertura ilustra el retraso de la ciudad en la implantación de este campo de la distribución si se compara con la vecina Asturias (FERNÁNDEZ GARCÍA, 2003; BENITO DEL POZO y LÓPEZ, 2004), región cuyos centros comerciales se benefician desde hace años de un intenso caudal de consumidores procedentes de León.

Esta iniciativa, promovida por la multinacional holandesa AM Multi Development Corporation, estaba incluida en un proyecto de más calado, que implicó la urbanización y edificación por parte del grupo Begar de un nuevo polígono residencial en la margen derecha del río Bernesga: denominado como re- 
sidencial Soto del Bernesga incluía más de 700 viviendas y el centro comercial concebido como una nueva centralidad en el extremo septentrional de la ciudad, contando con un área de influencia inmediata que incluía los populosos sectores de Eras de Renueva o el Crucero; en consecuencia, su inauguración fue el resultado de una ambiciosa iniciativa, tanto en el plano económico como urbanístico. Tipológicamente es un centro comercial y de ocio, patrón al que se ajusta la mayoría de los centros comercial abiertos desde principios de la presente década, y sus $37.000 \mathrm{~m}^{2}$ de superficie bruta alquilable lo enmarca dentro de los denominados centros comerciales medianos; con establecimientos locomotora de tamaño medio (un supermercado enseña Supercor, medias superficies en el campo de los electrodomésticos-Media Markt, Miró- y un multicine de la cadena Cinebox), una fuerte presencia de tiendas de moda (prácticamente la totalidad de las enseñas del grupo Inditex, H\&M, Sfera, Custo Barcelona....) y la restauración, en un marco dominado por el sucursalismo y la franquicia. La apertura de Espacio León ha significado la definitiva inclusión de la ciudad en el proceso de homogeneización del consumo a escala global, y tendrá pronta continuación con un nuevo proyecto de centro comercial de tamaño medio promovido por Martinsa-Fadesa y el grupo Ribera Norte aprovechado una gran parcela en Eras de Renueva. En definitiva, también en León se confirman las previsiones de ciertos autores para el conjunto de España (MUNUERA Y CUESTAS, 2006): continuación del crecimiento de los centros comerciales, cada vez más orientados hacia el ocio y con una mayor presencia en ciudades medias.

En lo que atañe al pequeño comercio tradicional, por lo menos el más cualificado, ha recurrido también a estrategias defensivas con implicaciones espaciales, concretadas en la conformación de un centro comercial abierto en torno a las principales arterias comerciales del centro urbano. Esta iniciativa se configura como un conjunto de acciones tendentes a la modernización y dinamización del pequeño comercio que tiene a la potenciación del asociativismo como principal rasgo de identidad. En 2002 se fusionan dos asociaciones de comerciantes -León Gótico y Centrópolis-, decidiendo la creación del Centro Comercial Abierto León Gótico, con el objetivo de alcanzar sinergias a partir de la creación de una imagen corporativa unificada, promover acciones de promoción conjuntas, emisión de tarjetas de fidelización y optar a mejores condiciones de financiación. El centro comercial abierto se extiende por la mayor parte de los distritos 1 y 2, en torno al eje Ordoño II-calle Ancha, ocupando la franja central del ensanche y el sector del Casco Histórico con mayor atractivo comercial y turístico. Esta delimitación no es casual, engarzando con una historia comercial marcada por el progresivo desplazamiento a lo largo de los siglos XIX y XX del centro de gravedad mercantil desde la plaza Mayor hacia Ordoño II (REGUERA, 1987; CORTIZO, 1999). 
La fórmula escogida por los comerciantes leoneses está bastante difundida en las ciudades españolas, pretende recrear una suerte de centro comercial a partir de los comercios radicados en las principales calles comerciales, imitando en lo posible las técnicas empleadas en los centros comerciales convencionales. Su finalidad es convertirse en un instrumento relevante de defensa del pequeño comercio radicado en los centros urbanos, de revitalización funcional de estos mismos centros e, incluso, como medio para incrementar la competitividad comercial frente a otras ciudades (CERDÁ, FERNÁNDEZ y REBOLLO, 2007; MEdiano, TAMAYO y TEJAdA, 2006; Elizagarate y ZorRiLla, 2004). Posiblemente en el caso de León no se alcance un nivel óptimo en el desarrollo del centro comercial abierto, especialmente en términos de imagen corporativa, rehabilitación de espacios urbanos y sinergias con equipamientos comerciales singulares (mercados municipales); pero si abre vías para lograr una superior cooperación entre los pequeños comerciantes radicados en el centro de la ciudad.

\section{La repercusión de la inmigración en la oferta comercial}

La presencia de inmigrantes es un fenómeno nuevo en el comercio local, se puede afirmar que el inicio de la presente centuria marca la aparición de un grupo compacto de comerciantes extranjeros que han consolidado en breve tiempo un nicho de mercado propio y diferenciado, aunque, eso sí, a costa de desplazar determinadas tipologías en boga a lo largo de los años 1990 (los bazares denominados popularmente "todo a 100", casi todos encuadrados dentro de lo que en este artículo se ha denominado comercio tradicional). Obviamente, estos inmigrantes en buena parte se corresponde con un grupo humano muy específico (concretamente chinos), que en un período extraordinariamente breve se han asentado en prácticamente la totalidad de las localidades españolas de cierto tamaño (existen ejemplos de este tipo en localidades de apenas 10.000 habitantes, sin ir más lejos y sin movernos de la provincia de León, como Astorga o La Bañeza). Pero también otros colectivos, en este caso de origen magrebí, han abierto establecimientos comerciales en fechas recientes, aunque esta vez dirigidos a miembros de su comunidad y sin apenas repercusión sobre el tejido comercial autóctono.

Antes de profundizar en el caso que nos ocupa vale la pena considerar algunos trabajos sobre el particular centrados en las principales ciudades españolas, pues pueden ofrecer algunas claves sobre la cuestión ya que este fenómeno está allí más avanzado y posee una entidad muy superior. El caso de Barcelona ha sido profusamente estudiado (ARAMBURU, 2002 y SERRA, 2006), ilustrando una doble realidad en la relación entre actividad mercantil e inmigración. Una primera interpretación (ARAMBURU, 2002) distingue un comercio en manos de inmigrantes y para inmigrantes (realidad cultural) y un comercio como oportu- 
nidad de integración social para la inmigración y alejamiento de la marginación. Una segunda alternativa (SERRA, 2006) alude a la distinción entre un modelo propio para Europa (comercio inmigrante como vía de supervivencia) y otro para Norteamérica (como instrumento de ascenso social), que son asimilables a la contraposición señalada por Aramburu. Para Madrid tenemos el estudio de GÓMEZ CRESPO (2006) sobre cuatro barrios de la capital, en la que entre sus principales aportaciones se encuentra, en primer lugar, el rechazo del concepto de comercio étnico, argumentando que todas las estrategias desarrolladas por estos comerciantes son similares a las llevadas a cabo por los comerciantes nacionales en situaciones parecidas (inmigración interna en los 1960 y los 1970) $\mathrm{y}$, en segundo término, una interesante reflexión en torno a la dualidad ejemplificada por una lógica capitalista (explicativa de la actual crisis del pequeño comercio) y otra concepción de los intercambios comerciales en los bordes del capitalismo (que ayuda a comprender la expansión de los comercios en manos de inmigrantes, bajo formatos propios del pequeño comercio tradicional) En definitiva, el comercio inmigrante obedece a lógicas de subsistencia, que, paradójicamente, emergen en momentos en que esta perspectiva se debilita entre los comerciantes autóctonos.

\section{a. $\quad$ Repercusión de la inmigración sobre el comercio en León}

A pesar de ser una ciudad poco atractiva para la inmigración, tanto ella como su provincia ha sido objeto de multitud de estudios (GONZÁLEZ PÉREZ y SOMOZA MEDINA, 2004; LÓPEZ TRIGAL, 1991; LÓPEZ TRIGAL y OTROS, 1994, pp. 73-115; LÓPEZ TRIGAL y OTROS, 2007, pp. 73-103). Estos trabajos ponen de manifiesto un cambio en el modelo inmigratorio asociado a la transformación del modelo de desarrollo económico de la provincia (crisis de la industria extractiva y de la agricultura, creciente terciarización de la economía), las consecuencias de este cambio sobre la inmigración se pueden sintetizar en los siguientes puntos:

1. Reubicación espacial de la inmigración. Las cuencas mineras dejan de concentrar el grueso del colectivo inmigrante, pues en los años 1960 y 1970 tanto el Bierzo Alto como Laciana concentraban los principales contingentes. En la actualidad las áreas urbanas de León y Ponferrada se tornan en los destinos elegidos por la comunidad inmigrante.

2. Cambio en la ocupación laboral de los inmigrantes. Si en décadas pasadas el trabajo en las minas emplea al grueso de la inmigración, desde fines de los 1990 los extranjeros encuentran ocupación en una gran diversidad de oficios dentro del sector servicios, entre ellos el comercio. 
Utilizando cifras del Padrón se demuestra el creciente atractivo que ejerce la capital sobre la inmigración: en 1996 existían censados en la provincia 5.943 inmigrantes, apenas del $1,16 \%$ de la población total, de los que 765 lo estaban en la capital, un escasísimo $0,53 \%$ de los efectivos demográficos capitalinos y un pobre $12,87 \%$ de los extranjeros radicados en la provincia. En 2006 la inmigración suma en la provincia 17.201 efectivos, un 3,45\% del padrón total, y los residentes en León suman 5.936, 4,33 \% de la población local y un estimable $34,51 \%$ de los inmigrantes leoneses.

Lógicamente, el rápido crecimiento de la comunidad inmigrante (en una década su número se ha septuplicado) tiene que tener consecuencias en el plano comercial, tanto en el plano del consumo (constituyen un nuevo nicho de consumidores, a pesar de su menor poder adquisitivo y tendencia al consumo) como en el de la oferta (también en León, aunque de manera mucho menos visible, comienzan a proliferar pequeños comercios en manos de inmigrantes).

En León se pueden apreciar ambos fenómenos. En el caso del comercio étnico (realidad cultural) el barrio del Crucero es un buen ejemplo: ese sector de la ciudad, un tanto olvidado desde la pérdida de protagonismo del ferrocarril, ha vivido una evidente decadencia, por no decir degradación. En estas circunstancias la población ha decaído, se ha producido un marcado envejecimiento y la calidad del parque inmobiliario se ha resentido. La consecuencia inmediata es que El Crucero alberga la vivienda más económica de la ciudad, ha atraído al grueso de la población inmigrante (predominantemente magrebí, en menor medida colombiana y rumana) y, consecuentemente, han sumido al barrio en un círculo vicioso en el que inmigración y marginación se retroalimentan. No sólo la vivienda se ve afectada por este fenómeno, también la actividad mercantil, observándose cierta tendencia hacia la sustitución del comercio tradicional autóctono por establecimientos en manos de inmigrantes que, en su inmensa mayoría, tienen como clientes a compatriotas que han ido ocupando las casas que la población local han dejado vacías. En este barrio, principalmente en las cercanías de la estación de Renfe y calles que desembocan en el tramo inicial de la avenida Doctor Fleming, han proliferado las carnicerías halal, locutorios y autoservicios que ofertan productos muy específicos y vinculados a los usos culturales de estos nuevos leoneses.

Pero el comercio inmigrante no se vincula únicamente a los angostos límites comunitarios y culturales, también es una vía de integración social. Este es el caso del comercio en manos de asiáticos, concretamente nacionales de la República Popular China, que se dedican mayoritariamente a la hostelería y el comercio teniendo como clientes no a connacionales ni a otros inmigrantes, sino a la población española. La irrupción de los comerciantes asiáticos es muy reciente, de hecho no existían ejemplo alguno en 1995 (en aquella época su presencia 
se limitaba al sector de la restauración), y han vivido una expansión tal que en la actualidad suman 35 (por señalar una fecha que sirva de referente, en 2003 existían cuatro establecimientos, lo que da idea de la rapidez en la expansión de este tipo de comercio), preferentemente en el sector del bazar, con un total de 28 establecimientos (su aparición acarreó la práctica extinción de los todo 100, comercio de bienes de precio reducido que proliferaron como consecuencia de la crisis económica sufrida entre 1992 y 1996), y ya muy lejos el textil, con cinco establecimientos (uno de ellos al por mayor). Sin entrar en las causas de la expansión de este comercio, común a toda España, únicamente señalar que la minimización de los costes hasta extremos difícilmente alcanzables por el comercio autóctono, las redes de solidaridad grupales y la reciente competitividad industrial del gigante chino son los puntales de su extraordinario crecimiento.

La ubicación de estos comercios es muy reveladora del mercado al que se dirigen. En su inmensa mayoría escogen los barrios, pues los distritos céntricos (1 y 2) suman únicamente 10 establecimientos (menos de un tercio del total). En el Ensanche, donde el precio de los locales y las características de la clientela no les interesan, aparecen únicamente en calles secundarias (la excepción viene de la mano de dos puntos de venta radicados en República Argentina); también son infrecuentes en el casco histórico, donde más que los precios de los locales les disuade la despoblación de este sector, de tal manera que únicamente he registrado dos establecimientos en la calle de la Rúa. En los barrios destacan la margen derecha del Bernesga (distrito 7, en especial sectores del Crucero y Pinilla) con ocho establecimientos, La Chantria y San Claudio (Distrito 6) con seis puntos de venta, y el Espolón y San Esteban (distrito 3) con cinco. En definitiva, el comercio asiático se ve indefectiblemente atraído por las áreas en las que viven población de menor capacidad adquisitiva.

\section{CONCLUSIONES}

A lo largo de este trabajo se ha desgranado algunas claves explicativas de las trasformaciones sufridas por la actividad mercantil en la ciudad de León en el período 1995-2006. En esta etapa, caracterizada por un continuado crecimiento económico, se ha analizado el comportamiento de las grandes ramas del comercio minorista (de consumo frecuente y especializado) y los cambios más relevantes dentro del colectivo de los comerciantes. Los principales resultados que se han obtenido se pueden sintetizar en los siguientes puntos:

El detallismo de consumo frecuente tiende a perder presencia en la estructura minorista, evolución lógica con la evolución del comportamiento de los consumidores. En términos de localización se caracteriza por el equilibrio y un mejor ajuste respecto a la localización de la población; de todos modos se aprecia una 
leve sobrerrepresentación del centro que se ve corregida levemente estos últimos años.

El detallismo especializado ha experimentado un notable crecimiento, en especial en los barrios. Los distritos centrales, aunque siguen siendo el principal polo comercial, han visto retroceder su tradicional preeminencia, beneficiándose los barrios aunque se forma extraordinariamente desigual al concentrarse el crecimiento en polos de actividad mercantil muy específicos (entorno de El Corte Inglés, Espacio León, Eras de Renueva).

Las dinámicas espaciales registradas, tanto por la distribución de bienes de consumo frecuente como la especializada, reflejan un desigual comportamiento de centro y periferia, circunstancia que se ha apuntado en otros estudios (DESSE, 1999; ESPINOSA, 2004). El centro urbano pierde poder de atracción y la ciudad, desde el punto de vista mercantil, se torna cada vez más compleja y diversa.

Desde el punto de vista del comerciante se van imponiendo paulatinamente las visiones economicistas sobre las sociales, la empresa sobre el pequeño comerciante tradicional. En estos años la tasa de penetración de los establecimientos bajo formas societarias se ha visto acrecentada extraordinariamente, con una presencia cada vez mayor de comerciantes foráneos y formatos innovadores que manifiestan la irreversible integración del mercado leonés en las tendencias globales. La gran distribución, bien mediante sucursales bien empleando franquicias, va arrinconando progresivamente al pequeño comercio tradicional que únicamente alcanza cierto grado de organización y dinamismo en los distritos centrales.

Un factor que contribuye a ilustrar esa superior interacción entre el comercio leonés, como realidad local, y las innovaciones y realidades a escala global, viene de la mano de los inmigrantes. El comercio en manos de inmigrantes, fenómeno aún incipiente en la ciudad, mantiene una estructura dual: comunitarista en el caso de un puñado de establecimientos en el estrecho marco de las comunidades nacionales muy concretas (sintomático es el caso de la comunidad marroquí), manifestación de la pujanza social de algunos colectivos (concretamente el chino) que intentan cubrir algunos nichos de mercado abandonados como consecuencia de la crisis del pequeño comercio tradicional de barrio.

\section{BIBLIOGRAFÍA}

ARAMBURU OTAZU, M. (2002), «Los comercios de inmigrantes extranjeros en Barcelona y la recomposición del "inmigrante" como categoría social», Scripta Nova, vol. VI, 108. 
BARATA SALGUEIRO, T. (1999), «Globalisation trends on retail development process», en BARAta SAlgueiro, T. (ed.), The globalization of consumption and retail places. Lisboa, Universidade de Lisboa, pp. 9-33.

BENITO DEL PozO, P. y LÓPEZ GONZÁLEZ, A. (2004), «Terciarización y nuevas formas de comercio en Asturias», Documents d'Anàlisi Geogràfica, 43, pp. 27-44.

CALderón CALderón, B. y GARcía Cuesta, J. L. (2006), «Formatos y estrategias para el control del espacio comercial urbano: el caso de Valladolid y su entorno», Scripta Nova, vol. X, 223.

CAMPESINO FERNÁNDEZ, A. J. (Coord.) (1999), Comercio, turismo y cambios funcionales en las ciudades españolas patrimonio de la humanidad. Cáceres, Cámara Oficial de Comercio e Industria de Cáceres.

CARreras I Verdaguer, C. (2000), «Cambios en las formas del comercio y el consumo en Barcelona», Estudios Geográficos, 238, pp. 103-123.

Casares Ripol, J. y Rebollo Arévalo, A. (1996), Distribución comercial. Madrid, Civitas.

Cerdá SuÁrez, L. M., Fernández Nogales, Á. y Rebollo Arévalo, A. (2007), «Atributos para el éxito de una zona comercial: una evidencia empírica en el municipio de Getafe», Distribución y Consumo, 95, pp. 16-31.

CorTizo Álvarez, T. (1999), «El ensanche de León. Proyecto y primera ocupación», en LÓPez Trigal, L. (Ed.), Los ensanches en el urbanismo español. El caso de León. Madrid, Biblioteca Nueva, pp. 83-113.

CRUZ Roche, I. (Coord.) (1999), Los canales de distribución de productos de gran consumo. Madrid, Pirámide.

DESSE, R. P. (2001), Le nouveau commerce urbain. Dynamiques spatiales et stratégies des acteurs. Rennes, Presses Universitaires de Rennes.

Durany CASTRILlo, Ma. P. (1990), La calle Ordoño II de León. De calzada real a eje comercial y de servicios. León, Universidad de León.

DURANY CASTRILlO, Mª P. (2004), La ciudad de León. Ordenación de su ecosistema urbano. León, Universidad de León.

EliZAGARATE, V. y ZORRILlA, P. (2004), «El comercio urbano como factor estratégico para la competitividad entre ciudades. Guipúzcoa: un caso de centro comercial abierto en red», Distribución y Consumo, 74, pp. 101-111.

ESPINOSA SEGUí, A. I. (2004), «Amenazas y estrategias del comercio de centro urbano. El caso de Alicante», Boletín de la Asociación de Geógrafos Españoles, 38, pp. 153174.

FERnÁNDEZ GARCÍA, A. (2003), «Hipermercados y centros comerciales en Asturias», Ería, 62, pp. 341-349.

GARCÍA EsCALONA, E. (2000), «Cambios en las formas y lugares de consumo en Madrid», Estudios Geográficos, 238, pp. 73-102.

GÓMEZ CRESPO, P. (2006), Inmigración y comercio en Madrid: empresarios, consumidores, trabajadores y vecinos. Madrid, Ayuntamiento de Madrid.

GONZÁlEZ GONZÁLEZ, Ma ${ }^{\mathrm{a}}$ J. (1987), Diferenciación socioeconómica en la ciudad de León. León, Universidad de León.

GONZÁLEZ GONZÁLEZ, Ma . J. (1999), «La evolución de la estructura demográfica y social del ensanche de León (1935-1996)», en LÓPEZ TrigAL, L. (Ed.), Los ensanches en el urbanismo español. El caso de León. Madrid, Biblioteca Nueva, pp. 143-171. 
GonZÁlez GonzÁlez, Ma . J.; GONZÁlEZ POLlEDO, L. A. y LÓPEZ TRIGAL, L. (1986), Guía urbana de León. León, Universidad de León-Junta de Castilla y León. GonzÁlez GonzÁlez, Ma . J. y PÉrez Llamazares, Ma. E. (2000), Atlas social de la ciudad de León. León, Universidad de León.

GonzÁlez PÉrez, J. M. y Somoza Medina, J. (2004), «Territoire et inmigration en Espagne. Une étude de cas en Palma de Mallorca et León». Cybergeo: Revue Européenne de Géographie, 274.

LÓPEZ GonZÁLEZ, A. (2001a), «Detallismo e espacio na cidade de Lugo. Unha aproximación á localización no espacio do comercio minorista», Boletín do Museo Provincial de Lugo, IX, pp. 101-121.

LÓPEZ GONZÁLEZ, A. (2001b), «Transformacións comerciais recentes na cidade de Ourense», Sémata, 11, pp. 261-280.

LÓPEZ GonZÁLEZ, A. (2003), «Estructura y dinámica del comercio en Cuenca», Investigaciones geográficas, 32, pp. 139-156.

LÓPEZ GONZÁlEZ, A. (2005), «Fuentes en el estudio de la Geografía del comercio», en Homenaje a Joaquín González Vecín. León, Universidad de León, pp. 323-331.

LóPEZ Trigal, L. (1987), La ciudad de León y su alfoz. León, Diputación de LeónUniversidad de León.

LÓPEZ TRIGAL, L. (1991), La inmigración extranjera en León: análisis de su estructura y distribución en la provincia y las cuencas mineras. León, Universidad de León.

LÓPEZ TRIGAL, L. Y OTROS (1994), La migración de portugueses en España. León, Universidad de León.

LÓPEZ TRIGAL, L. (1999), «El papel central y valoración del Ensanche de León, cien años después de su proyecto», en LÓPEZ TRIGAL, L. (Ed.), Los ensanches en el urbanismo español. El caso de León. Madrid, Biblioteca Nueva, pp. 173-205.

LÓPEZ TRIGAL, L. (Dir.) (2002), Las ciudades leonesas. Guía crítica desde la Geografía. León, Universidad de León.

López Trigal, L., Cortizo Álvarez, J. y LóPez GonzÁlez, A. (2007), Población y vivienda en la provincia de León. León, Universidad de León.

MEdiano, L., TAMAYO, U. y TEJADA, S. (2006), «Asociacionismo comercial espacial y revitalización urbana. El caso de Bilbao», Distribución y Consumo, 86, pp. 48-58.

Molina Collado, A. (2002), «Los servicios y las actividades comercial y turística en ciudades históricas españolas», Distribución y Consumo, 55, pp. 39-49.

Munuera Alemán, J. L. y Cuestas DíAZ, P. J. (2006), «Factores de atracción de los centros comerciales en España», Información Comercial Española, 828, pp. 99-116.

REgUeRA RodrígueZ, A. T. (1987), La ciudad de León en el siglo XX. Teoría y práctica en el urbanismo local, León, Colegio Oficial de Arquitectos de León.

Ruiz Palomeque, E., POZO RIVERA, E. y LÁzaro Torres, Má. L. DE (2000), «Nuevas formas de comercio y consumo en Madrid. Las grandes superficies», Estudios Geográficos, 238, pp. 125-143.

SERra Del Pozo, P. (2006), «l comercio de los inmigrantes en el centro histórico de Barcelona», Estudios Geográficos, 261, pp. 635-672.

TOMÉ FERnÁnDEZ, S. (1979), Usos del suelo en el casco intramuros de León. León, Universidad de León. Tesis de licenciatura, inédita. 
Mapa 1. Delimitación de los distritos censales

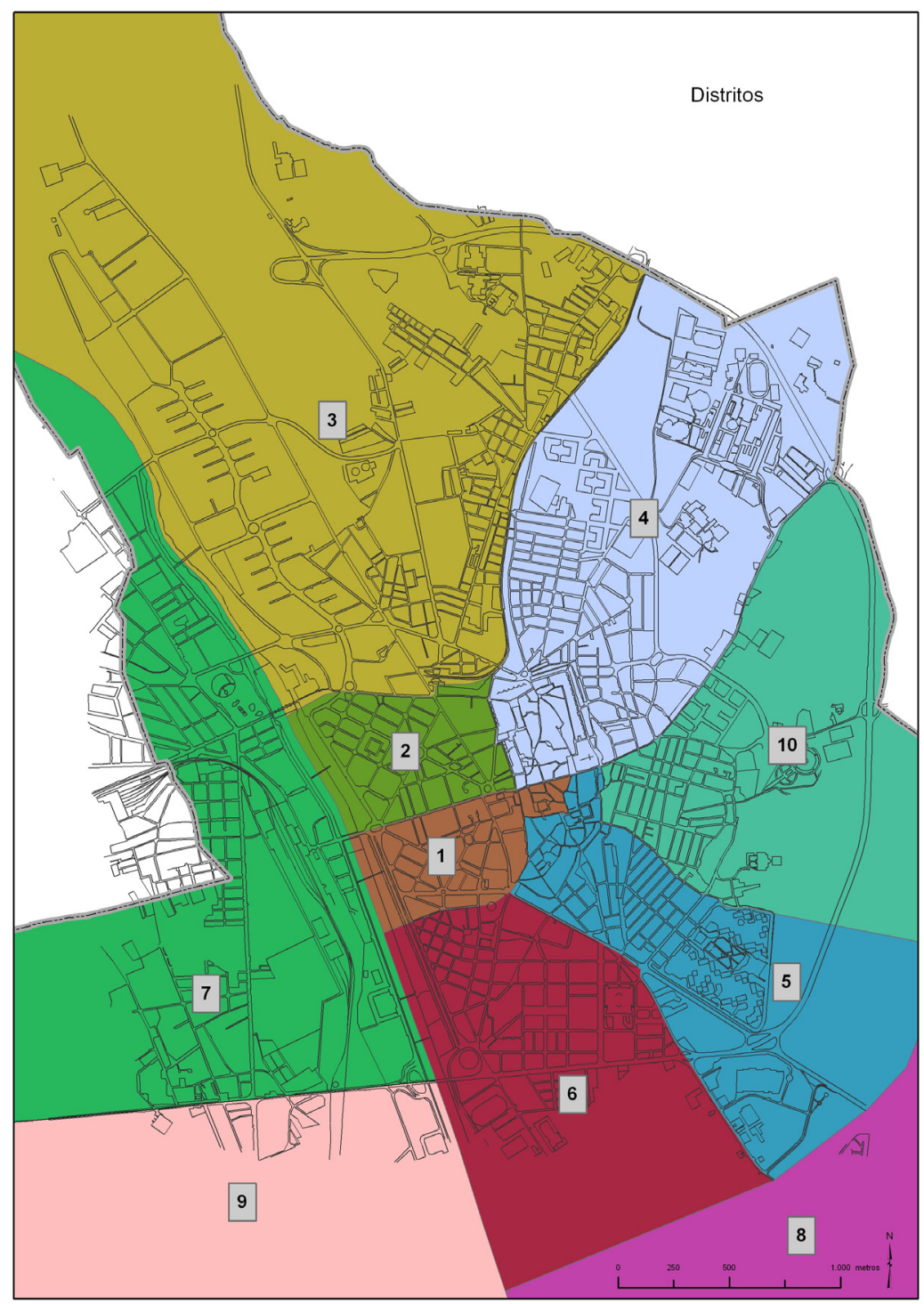

Fuente: Elaboración propia 
Mapa 2. Evolución del comercio al detalle de consumo frecuente

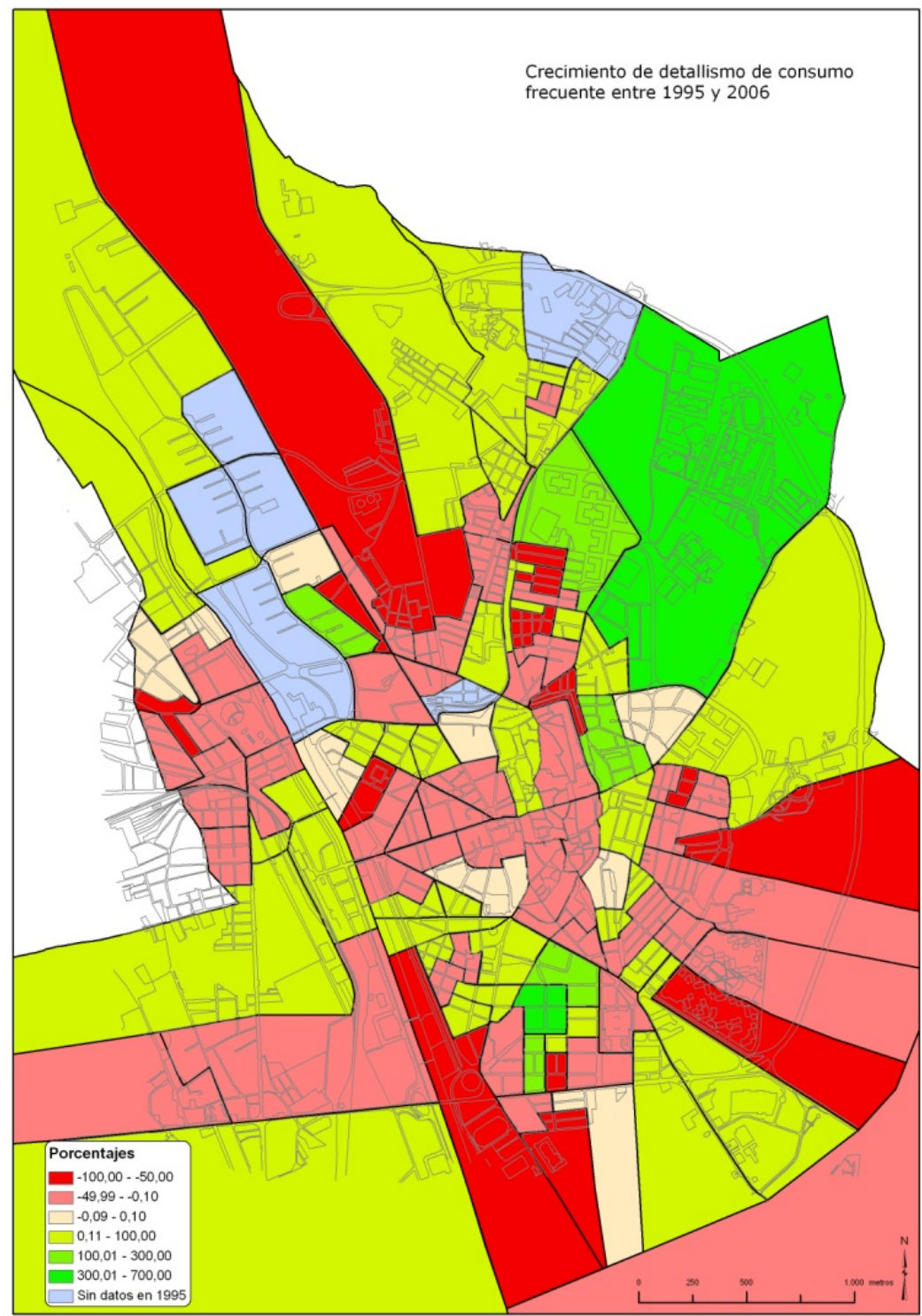

Fuente: Elaboración propia 
Mapa 3. Evolución del comercio al detalle especializado

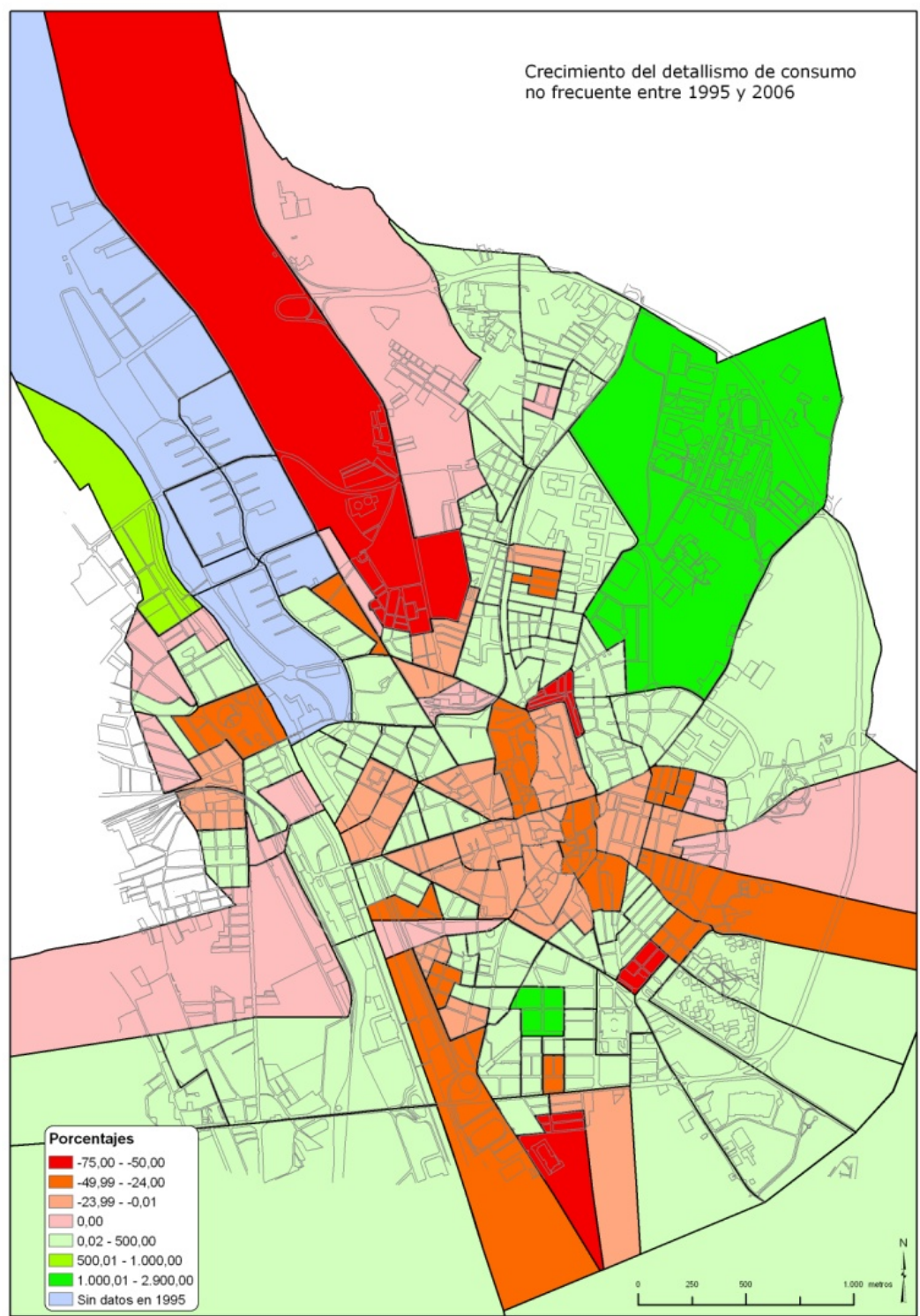

Fuente: Elaboración propia

Polígonos. Revista de Geografia, 17 (2007); pp. 83-111 
Mapa 4. Variación de los establecimientos regentados por formas societarias (no autónomos) entre 1995 y 2006

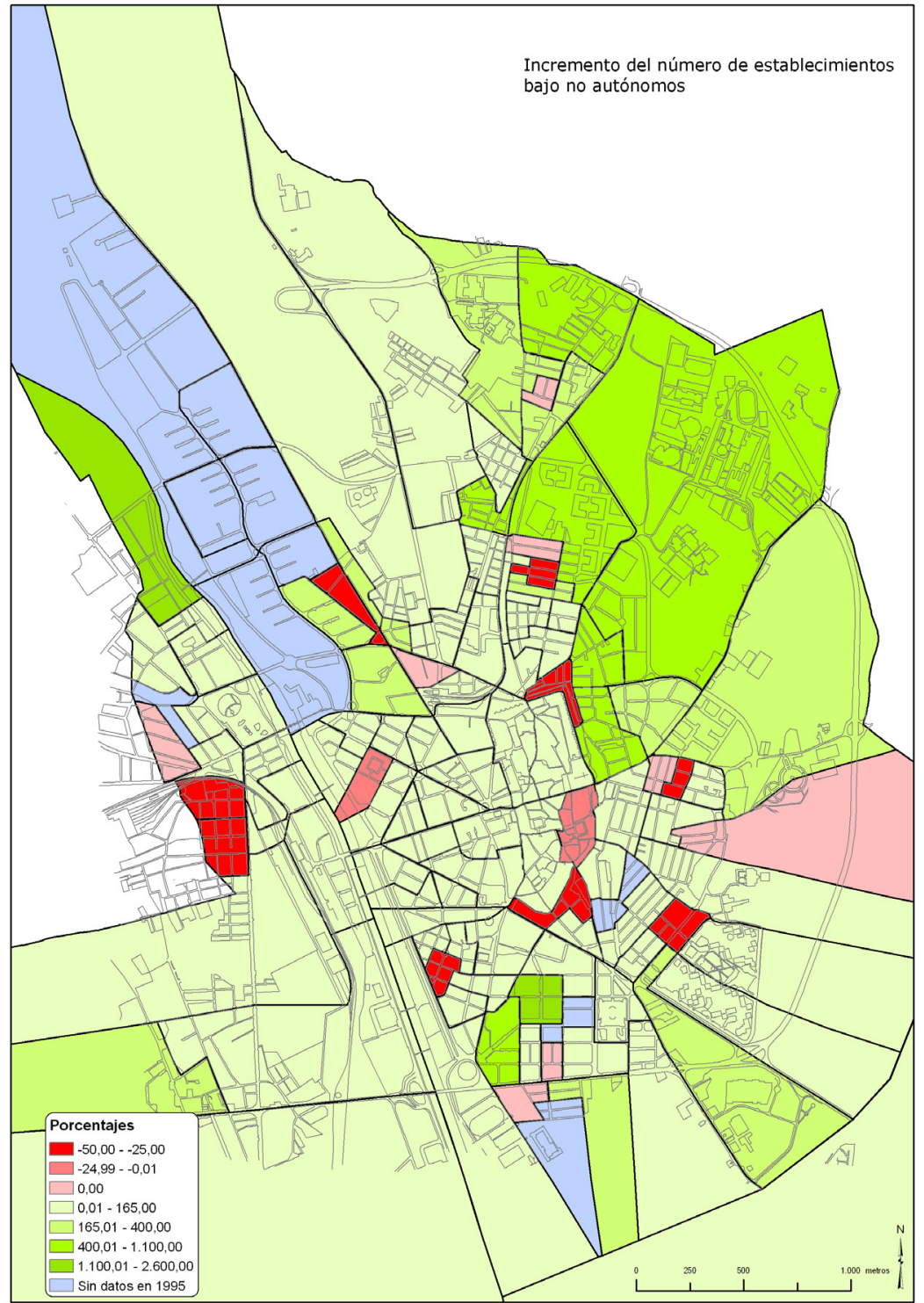

Fuente: Elaboración propia

Polígonos. Revista de Geografía, 17 (2007); pp. 83-111 